\title{
Role of thiamine in Huntington's disease pathogenesis: In vitro studies
}

\author{
Beata M. Gruber-Bzura ${ }^{A-D}$, Jolanta Krzysztoń-Russjann ${ }^{B, C}$, , Irena Bubko ${ }^{B}$, Jarosław Syska ${ }^{B}$, Małgorzata Jaworska ${ }^{B, C, E}$, \\ Adam Zmysłowski ${ }^{B, C}$, Magdalena Rosłon ${ }^{B, C}$, Janina Drozd ${ }^{B}$, Ewa Drozd ${ }^{B}$, Edyta Majorczyk ${ }^{B, C}$, Elżbieta L. Anuszewska ${ }^{E, F}$ \\ Department of Biochemistry and Biopharmaceuticals, National Medicines Institute, Warszawa, Poland \\ A - research concept and design; B - collection and/or assembly of data; $\mathrm{C}$ - data analysis and interpretation; \\ $\mathrm{D}$ - writing the article; $\mathrm{E}$ - critical revision of the article; $\mathrm{F}$ - final approval of article
}

\author{
Address for correspondence \\ Beata Gruber \\ E-mail:b.gruber@nil.gov.pl \\ Funding sources \\ None declared \\ Conflict of interest \\ None declared
}

Received on 0ctober 30, 2015 Revised on February 14,2016 Accepted on May 10, 2016

DOI

10.17219/acem/63091

\section{Copyright}

Copyright by Author(s)

This is an article distributed under the terms of the

Creative Commons Attribution Non-Commercial License

(http://creativecommons.org/licenses/by-nc-nd/4.0/)

\begin{abstract}
Background. Oxidative stress accompanies neurodegeneration and also causes abnormalities in thiamine-dependent processes. These processes have been reported to be diminished in the brains of patients with several neurodegenerative diseases.

Objectives. The aim of this work was to conduct a comparative analysis of the impact of supplemented thiamine on the viability of human B lymphocytes with CAG abnormal expanded huntingtin gene (mHTT) (GM13509) and control, B lymphocytes without mHTT (GM14467) through the following studies: determination of the supplemented thiamine concentrations, which are effective for cell growth stimulation after incubation in thiamine deficit conditions; determination of cell capability to intake the exogenous thiamine; evaluation of exogenous thiamine influence on the profile of the genes related to thiamine and energy metabolism; determination of ATP synthesis and activities of thiamine-dependent enzymes, KGDHC and $B C K D H C$ in the intact cells and upon the exogenous thiamine.
\end{abstract}

Material and methods. The following methods were used: EZ4U test for cell growth analysis; HPLC for determination of thiamine intake and ATP synthesis, qRT-PCR for evaluation of the gene profiles and spectrophotometric method for KGDHC and BCKDHC activities determination.

Results. Maximal cell growth stimulation was observed at $2.5 \mathrm{mM}$ in GM14467 up to 135\% of the control culture and at $5.0 \mathrm{mM}$ in GM13509 cells up to 165\% of the control culture. Native levels of total ATP and KGDHC and BCKDHC activities in both cell types were comparable and did not changed upon thiamine deficit or supplementation. GM13509 cells showed more of an increase in growth stimulation upon thiamine supplementation than GM14467 cells and this effect was reflected in the increase of intracellular thiamine concentration.

Conclusions. The above results and reported changes in expression of GAPDH, IDH1 and SLC19A3 genes observed upon thiamine deficit conditions suggest that intracellular thiamine status and energy metabolism can have a role in HD pathogenesis.

Key words: thiamine, energy metabolism, Huntington's disease, ATP synthesis 
Huntington's disease (HD) is an autosomal dominant neurodegenerative disease with age-dependent complete penetrance. Like many neurodegenerative diseases, it is characterized by a cascade of events leading to neuronal death. In HD subjects there is strong evidence for reduced glucose consumption in the brain, even in presymptomatic mutation carriers. Reduced ATP synthesis was found in immortalized HD striatal neuronal cell lines. ${ }^{1}$ According Mochel et al., various mechanisms that underlie the energy deficit in HD phenotype have been proposed, including impaired oxidative phosphorylation, oxidative stress, impaired mitochondrial calcium handling, abnormal mitochondria trafficking, and deregulation of key factors of mitochondrial biogenesis or decreased glycolysis. ${ }^{1}$ Subcellular abnormalities were observed not only in tissues of the central nervous system (CNS) but also in peripheral tissue cells, such as fibroblasts, lymphocytes and erythrocytes of HD subjects. $^{2}$ This suggests that clues to the HD pathogenesis may be detectable outside the brain. In fact, decreased ATP/ADP ratio was observed in HD patient-derived lymphoblastoid cell lines, which inversely correlated with the length of the mutant polyglutamine tract. ${ }^{1} \mathrm{Mu}$ tant huntingtin was reported to affect the activity of mitochondrial complex I in the skeletal muscles of patients with HD. ${ }^{3}$ Schapira mentioned that complex I deficiency had been found in HD platelets. ${ }^{4}$

Respiratory chain defects increase reactive oxygen species (ROS) production. Evidence of enhanced oxidative stress in HD brains includes an increase in the accumulation of lipofuscin, a product of unsaturated fatty acids peroxidation or oxidative modification of proteins and lipids, also increased in HD brain and in animal models. ${ }^{1}$ Gil-Mohapel et al. in their review presented an overview of preclinical and clinical studies that have indicated a link between oxidative stress, neurodegeneration and cell death in HD. ${ }^{5}$ Oxidative stress accompanies neurodegeneration and also causes abnormalities in thiamine-dependent processes. These processes have been reported to be diminished in the brains of patients with several neurodegenerative diseases. ${ }^{6}$ Aikawa et al. showed that encephalopathic rats had brain thiamine levels lower than $20 \%$ that those of the control group and ATP concentrations were $89.5 \%$ of normal controls. ${ }^{7}$ Thiamine diphosphate (TDP) is the essential cofactor for key enzymes of energy metabolism. The TDP-dependent enzymes in brain include cytosolic enzyme transketolase, a key enzyme of the pentose phosphate shunt and 3 mitochondrial enzyme complexes, i.e. pyruvate dehydrogenase complex (PDHC), which links glycolysis and Krebs cycle (tricarboxylic acid cycle), $\alpha$-ketoglutarate dehydrogenase complex (KGDHC), postulated to be a rate-limiting step of Krebs cycle and the branched chain $\alpha$-keto acid dehydrogenase complex (BCKDHC), which provided a means for branched chain amino acids to enter Krebs cycle. ${ }^{6}$ Pekovich et al. showed that mRNA levels of transketolase and E1 $\beta$ subunit of pyruvate dehydrogenase complex in human fibroblasts, lymphoblasts and neuroblastoma cells were lower in thiamine-deficient cultures. ${ }^{8}$ Decreased activity of thiamine-dependent enzymes leads to a cascade of events that include focal decreases in energy status, oxidative stress, lactic acidosis, decreased glucose utilization, immediate-early gene induction and inflammation. ${ }^{9}$ As showed by Gibson and Zhang, vitamin E and butylated hydroxyanisole provide significant neuroprotection to thiamine deficient neurons in cultures and regarded that thiamine as a selected antioxidant may be useful in terms of revealing the role of thiamine dependent processes in disease and other conditions that lead to altered neuronal function. ${ }^{6}$

The aim of this study was to conduct a comparative analysis of the impact of thiamine supplementation on the viability of human B lymphocytes with CAG expanded huntingtin gene and normal cells through the studies on the following items: (1) determination of the supplemented thiamine concentrations that are effective for cell growth stimulation after incubation in thiamine deficit conditions (obtained by the treatment of cells with pyrithiamine hydrobromide); (2) evaluation of cell capability to intake the supplemented thiamine from the culture medium; (3) determination of the profile of genes related to thiamine and/or energy metabolism in the intact cells and upon the exogenous thiamine treatment; (4) determination of mitochondrial ATP synthesis and activity of thiamine-dependent enzymes, KGDHC and BCKDHC in the intact cells and upon the exogenous thiamine.

\section{Material and methods}

\section{Cells}

EBV-immortalized B lymphocyte cell lines derived from B lymphocytes collected from peripheral blood of healthy female donor - GM14467 and B lymphocytes from peripheral blood of HD female donor with expanded CAG repeat located in the coding region of the huntingtin gene - GM13509 (both B lymphocytes cell lines were purchased in Coriell Institute for Medical Research, USA), were kept in RPMI 1640 with glutamine, $10 \%$ FBS and $1 \%$ antibiotics solution (penicillin, streptomycin, amphotericin) (Lonza, Walkersville, USA).

\section{Cell viability}

Cell cultures $\left(3 \times 10^{5}\right.$ cells $\left./ \mathrm{mL} ; 25 \mathrm{~mL}\right)$ were growing for 3 days with pyrithiamine hydrobromide, 600 nM (Sigma-Aldrich). Then pyrithiamine was rinsed off, the cells were seeded onto 96-well plate and exposed to thiamine 
hydrochloride (Sigma-Aldrich) (0.2-6.0 mM) for $24 \mathrm{~h}$. After that time, the EZ4U test (Biomedica) was carried out according to the manufacturer's instruction. All experiments were related to the reference cultures to eliminate the impact of thiamine present in the RPMI 1640. The reference cultures included: the cells kept for 4 days in unmodified RPMI 1640 (control), the cells kept with pyrithiamine - throughout all incubation time (4 days) (TDM Pyri), the cells kept for 3 days with pyrithiamine and for the next $24 \mathrm{~h}$ with the intact RPMI 1640 (TDM). The latter one, TDM was treated as $100 \%$.

Two concentrations of thiamine for each cell line were selected for further studies, i.e. the minimal and maximal values, which increased cell viability. The results were expressed as \% of viable cells vs. thiamine concentration with \pm SD values calculated from 23 independent experiments.

\section{Intracellular thiamine concentration}

Cell cultures $\left(3 \times 10^{5}\right.$ cells $\left./ \mathrm{mL} ; 25 \mathrm{~mL}\right)$ were growing for 3 days with pyrithiamine hydrobromide, $600 \mathrm{nM}$. Then pyrithiamine was rinsed off, the cells were seeded into the next flask and exposed for $24 \mathrm{~h}$ to thiamine hydrochloride at the concentrations 0.5 and $2.5 \mathrm{mM}$ for GM1447 cells and 1.0 and $5.0 \mathrm{mM}$ for 13509 cells. Thiamine concentrations were selected on the basis of the EZ4U test. All calculations regarded the reference cultures as mentioned above. Thiamine and TDP were determined after derivatization with potassium ferricyanide. Cell lysates, which were prepared in trichloroacetic acid, were derivatized as mentioned above and then injected onto the chromatographic column.

\section{HPLC conditions}

Column: PRP-1; $150 \times 4.1 \mathrm{~mm}, 5 \mu \mathrm{m}$ with precolumn; column temperature: $25^{\circ} \mathrm{C}$; mobile phase: buffer (sodium dihydrogen phosphate $50 \mathrm{mM}$ + tetrabutylammonium hydrogensulfate $8.8 \mathrm{mM}), \mathrm{pH}=8.0$ : acetonitrile $(9: 1 \mathrm{v} / \mathrm{v})$; flow rate: $1.0 \mathrm{~mL} / \mathrm{min}$; fluorometric detection at: $\mathrm{Ex}=365 \mathrm{~nm} ; \mathrm{Em}=433 \mathrm{~nm}$; injection volume: $100 \mu \mathrm{L}$. The results were presented as ng/mg protein.

\section{Protein assay}

Protein was determined with Bio-Rad Protein Assay (Bio-Rad).

\section{Statistical analysis}

All the data was presented as mean \pm SD of 23 independent experiments and analyzed with Medistat System (microcomputer statistical system for medicinal purposes, v. 2.1; 1992). The results with $\mathrm{p}<0.05$ were considered significant.

\section{Profile of genes related with thiamine and energy metabolism}

\author{
RNA isolation
}

RNA was extracted from tested cell lines using the GeneMATRIX Universal RNA/miRNA Purification Kit (EURx Ltd. Biotechnology, Gdynia, Poland; www.eurx. com.pl) according to the manufacturer's protocol. The purity was verified by optical density (OD) ratio $\mathrm{OD}_{260 \mathrm{~nm}} /$ $\mathrm{OD}_{280 \mathrm{~nm}}$ and $\mathrm{OD}_{260 \mathrm{~nm}} / \mathrm{OD}_{230 \mathrm{~nm}}$ ranging from 1.85 to 2.05 and the integrity was evaluated by electrophoresis on Gel - RNA Flash Gel System (Lonza Rockland Inc., Rockland, USA). RNA templates before reverse transcription were additionally digested by DNaseI (Thermo Fisher Scientific Inc., USA; http://www.thermoscientificbio.com/ fermentas) according tothe manufacturer's protocol for preparation of DNA-free RNA.

\section{Reversed transcription (RT)}

Total RNA was reverse-transcribed using the PrimeScript RT-PCR kit II (Takara Bio Inc., Otsu, Shiga, Japan) for first-strand cDNA synthesis using $2.5 \mu \mathrm{M}$ oligonucleotides primer and 5.0 $\mu \mathrm{M}$ random hexamer for the priming method according to the manufacturer's recommendations. Synthesis was started with the incubation of the transcription mixture at $37^{\circ} \mathrm{C}$ for $30 \mathrm{~min}$ to initiate the reverse transcriptase reaction. Finally, reverse transcription was stopped by heating the reaction mixture for $5 \mathrm{~s}$ at $85^{\circ} \mathrm{C}$.

\section{qRT-PCR}

Gene expression was performed using qPCR analyses and was designed for genes listed in Table 1 using the Mx3005P qPCR System (Stratagene, La Jolla, USA). qRTPCR was carried out with SYBR Premix Ex Taq (TaKaRa, Japan) using 400 ng cDNA template into a sample-specific working solution prepared for 96-well plate according to Lonza Inc. (US) recommendations for StellArrays (www.lonza.com/arrays).

The relative transcription level was calculated based on $\Delta \Delta \mathrm{Ct}$ (cycle threshold) type of analysis using the 2- $\Delta \Delta C$ t method in order to Fold Change (FC) value determination between compared groups. Normalization to $18 \mathrm{~S}$ rRNA was used as internal control, and 9 additional gene normalizers, simultaneously distinguished by GPR software analysis, were performed for each gene tested. ${ }^{10}$

\section{Statistical analysis}

The data obtained from qPCR was analyzed by Global Pattern Recognition statistical software (GPR; https:// array.bhbio.com/BHB/GUI/AP/GPR.aspx). The GPR was 
Table 1. Subset of genes analysed with qPCR)

\begin{tabular}{|c|c|c|c|}
\hline Gene ID & Gene symbol & Protein name & $\begin{array}{c}\text { Enzyme } \\
\text { commission } \\
\text { number }\end{array}$ \\
\hline \multicolumn{4}{|c|}{ Control and normalizer genes } \\
\hline 2 & HSGenomic & HSGenomic & \\
\hline 1 & Hs18s & Hs18s & \\
\hline 60 & ACTB & PS1TP5-binding protein 1; actin, & \\
\hline 3251 & HPRT1 & hypoxanthine phosphoribosyltransferase 1 & EC2.4.2.8 \\
\hline 549 & AUH & AU RNA binding protein/enoyl-CoA hydratase & EC4.2.1.18 \\
\hline \multicolumn{4}{|c|}{ Thiamine metabolism closely related genes } \\
\hline 27010 & TPK1 & thiamine pyrophosphokinase 1 & EC2.7.6.2 \\
\hline 79178 & THTPA & thiamine triphosphatase & EC3.6.1.28 \\
\hline 7086 & TKT & transketolase & EC2.2.1.1 \\
\hline 8050 & $\mathrm{PDHX}$ & pyruvate dehydrogenase complex, component $X$ & no data \\
\hline 5160 & PDHA1 & pyruvate dehydrogenase (lipoamide) alpha 1 & EC1.2.4.1 \\
\hline 1629 & DBT & dihydrolipoamide branched chain transacyl+6ase E2 & EC2.3.1.168 \\
\hline 1737 & DLAT & dihydrolipoamide S-acetyltransferase & EC2.3.1.12 \\
\hline 593 & BCKDHA & branched chain keto acid dehydrogenase E1, alpha polypeptide & EC1.2.4.4 \\
\hline 594 & BCKDHB & branched chain keto acid dehydrogenase E1, beta polypeptide & EC1.2.4.4 \\
\hline 60386 & SLC25A19 & solute carrier family 25 (mitochondrial thiamine pyrophosphate carrier), member 19 & \\
\hline 80704 & SLC19A3 (THTR2) & solute carrier family 19, member 3 & \\
\hline 6573 & SLC19A1 & solute carrier family 19 (folate transporter), member 1 & \\
\hline 10560 & SLC19A2 (THTR1) & solute carrier family 19 (thiamine transporter), member 2 & \\
\hline \multicolumn{4}{|c|}{ Glycolysis, citrate cycle (TCA cycle, Krebs cycle) related genes } \\
\hline 2597 & GAPDH & glyceraldehyde-3-phosphate dehydrogenase & EC1.2.1.12 \\
\hline 5091 & PC & pyruvate carboxylase & EC6.4.1.1 \\
\hline 48 & ACO1 & aconitate hydratase & EC4.2.1.3 \\
\hline 3417 & IDH1 & isocitrate dehydrogenase 1 & EC1.1.1.42 \\
\hline 3419 & IDH3A & isocitrate dehydrogenase $3(\mathrm{NAD}+)$ alpha & EC1.1.1.41 \\
\hline 4967 & $\mathrm{OGDH}$ & oxoglutarate (alpha-ketoglutarate) dehydrogenase (lipoamide) & EC1.2.4.2 \\
\hline 1738 & DLD & dihydrolipoamide dehydrogenase, E3 & EC1.8.1.4 \\
\hline 1743 & DLST & dihydrolipoamide S-succinyltransferase (E2 component of 2-oxo-glutarate complex) & EC2.3.1.61 \\
\hline 8802 & SUCLG1 & succinyl-CoA synthetase alpha subunit & EC6.2.1.4 \\
\hline 6389 & SDHA & succinate dehydrogenase complex A & EC1.3.5.1 \\
\hline 2271 & $\mathrm{FH}$ & fumarate hydratase & EC4.2.1.2 \\
\hline 4190 & $\mathrm{MDH} 1$ & malate dehydrogenase & EC1.1.1.37 \\
\hline 47 & ACLY & ATP citrate & EC2.3.3.8 \\
\hline 1431 & CS & citrate synthase & EC2.3.3.1 \\
\hline
\end{tabular}


used to determine the gene transcript level changes for the GM13509 with reference to the GM14467 (calibrator) using $\mathrm{Ct}$ values obtained for all the genes tested. The GPR FC value was calculated for each gene. The results with $\mathrm{p}<0.05$ were considered significant.

\section{ATP synthesis}

Each reference culture and sample was prepared in parallel, i.e. with or without oligomycin $(1 \mathrm{mg} / \mathrm{mL})$ and $\mathrm{P}^{1}, \mathrm{P}^{5}$-di(adenosine-5') pentaphosphate (Ap5A) (0.15 mM) added before the measurement. Thiamine concentrations were as given above. All calculations regarded the reference cultures as described in cell viability. ATP synthesis was measured in whole cell lysates obtained by sonification of the cells in ice for $10 \mathrm{~min}$. Cell lysates were centrifuged and supernatants were directly injected onto the chromatographic column.

\section{HPLC conditions}

Column: Nova-Pak C18 $150 \times 3.9$ mm $4 \mu \mathrm{m}$; column temperature: $25^{\circ} \mathrm{C}$; gradient system: mobile phase A: sodium dihydrogen phosphate $25 \mathrm{mM}+$ tetrabutylammonium hydrogensulfate $100 \mathrm{mg} / \mathrm{L}, \mathrm{pH}=5.0$; mobile phase B: sodium dihydrogen phosphate $200 \mathrm{mM}$ + tetrabutylammonium hydrogensulfate $100 \mathrm{mg} / \mathrm{L}+$ acetonitrile $100 \mathrm{~mL} / \mathrm{L}, \mathrm{pH}=4.0$; flow rate: $0.7 \mathrm{~mL} / \mathrm{min}$; detection wavelength: $260 \mathrm{~nm}$; injection volume: $50 \mu \mathrm{L}$. $^{14}$ The results were presented as $\mathrm{nmol} / \mathrm{mg}$ protein.

\section{Statistical analysis}

All the data was presented as mean \pm SD of 2 independent experiments and analyzed with Medistat System (microcomputer statistical system for medicinal purposes, v. $2.1 ; 1992)$. The results with $\mathrm{p}<0.05$ were considered significant.

\section{KGDHC and BCKDHC activity}

Cell cultures $\left(2 \times 10^{5}\right.$ cells $\left./ \mathrm{mL}, 75 \mathrm{~mL}\right)$ were growing for 3 days in a culture medium containing $600 \mathrm{nM}$ pyrithiamine hydrobromide and further treated as described above. The reference cultures included: the cells kept for 4 days in unmodified RPMI 1640 (control), the cells kept with pyrithiamine - throughout all incubation time (4 days) (TDM Pyri), the cells kept for 3 days with pyrithiamine and for the next $24 \mathrm{~h}$ with the intact RPMI 1640 (TDM). After incubation, the culture medium was removed by centrifugation and the cells were washed twice with phosphate buffered saline solution without $\mathrm{Ca} / \mathrm{Mg}$ (PBS). Cell lysates were obtained by resuspension of the cell pellets with lysis buffer $(50 \mathrm{mM}$ Tris- $\mathrm{HCl}$; $5 \mathrm{mM}$ EDTA, $\mathrm{pH}$ 7.4) to get final concentration $50 \times 10^{6}$ cells/mL.

\section{KGDHC activity assay}

The assay was performed with the use of 96-well plates. Enzymatic activity assay was conducted at $37^{\circ} \mathrm{C}$ in reaction mixture containing Tris- $\mathrm{HCl} \mathrm{pH} 7.4$ buffer (50 mM), $1 \mathrm{mM} \mathrm{MgCl}$; $0.05 \mathrm{mM} \mathrm{CaCl}_{2} ; 0.05 \mathrm{mM}$ EDTA; $0.3 \mathrm{mM}$ thiamine pyrophosphate (TPP); $0.1 \%$ w/v Triton X-100; 0.3 mM DTT (dithiothreitol); $3 \mathrm{mM}$ NAD ( $\beta$-nicotinamide adenine dinucleotide); $0.2 \mathrm{mM}$ CoA (coenzyme A). Reaction was started after $20 \mu \mathrm{L}$ substrate solution was added ( $3 \mathrm{mM} \alpha$-ketoglutaric acid disodium salt) to the well containing preheated reaction mixture $(160 \mu \mathrm{L})$ and cell lysate $(20 \mu \mathrm{L})$. All reagents were purchased from Sigma Aldrich. The method was based on monitoring the NADH formation by reading the absorbance change at $340 \mathrm{~nm}$ within the time frame of $10 \mathrm{~min}$. The absorbance rate was corrected by respective blank substraction (reaction performed with water added instead of substrate solution). KGDHC specific activity was calculated with regard to molar extinction coefficient of $\mathrm{NADH}$ and expressed in $\mathrm{nmol} /(\mathrm{min} \times \mathrm{mg}$ protein $)$.

\section{BCKDHC activity assay}

The assay was performed with the use of 96-well plates. Enzymatic activity assay was conducted at $37^{\circ} \mathrm{C}$ in a reaction mixture of the composition described for KGDHC assay but with the addition of $5 \mathrm{mM}$ L-carnitine. The method was based on monitoring the decrease of substrate k-Ile (keto-isoleucine sodium salt (k-Ile), $3 \mathrm{mM}$, Sigma Aldrich) content in the time monitored by specific colorimetric reaction with DNPH (2,4-dinitrophenylhydrazine, $\mathrm{POCH}$ ) at $450 \mathrm{~nm} .^{15}$ The absorbance rate was corrected by a respective blank substraction (reaction performed as above). BCKDHC specific activity was calculated with regard to calibration curve prepared from k-Ile solution in a range of $1.5-3.0 \mathrm{mM}$ and expressed in $\mathrm{nmol} /(\min \times \mathrm{mg}$ protein $)$.

\section{Statistical analysis}

Data analysis was performed using Systat software v. 13 (Systat Software Inc., USA). The results of KGDHC and BCKDHC activity, expressed in $\mathrm{nmol} /(\mathrm{min} \times \mathrm{mg}$ protein $)$ and as the percentage relative to control, were obtained in 5-7 independent experiments. Resulted values were analyzed using descriptive statistics and presented as mean \pm SD. Differences between groups were assessed using the analysis of variance (one-way or two-way ANOVA) at a significance level $\alpha=0.05$ with appropriate post-hoc test selection (Gabriel test for between-groups comparison; Dunnett procedure to test differences from control group). Results with $\mathrm{p}<0.05$ were considered significant. 
Fig. 1. Influence of thiamine supplementation on GM14467 cells. $\mathbf{\Delta}$ - the cells kept with pyrithiamine hydrobromide $(600 \mathrm{~nm})$ throughout the whole incubation time (4 days) (TDM Pyri), - the cells kept for 3 days with pyrithiamine and for the next $24 \mathrm{~h}$ in the intact RPMI 1640 (TDM); - the cells exposed to thiamine for $24 \mathrm{~h}$. Bars represent the mean \pm SD

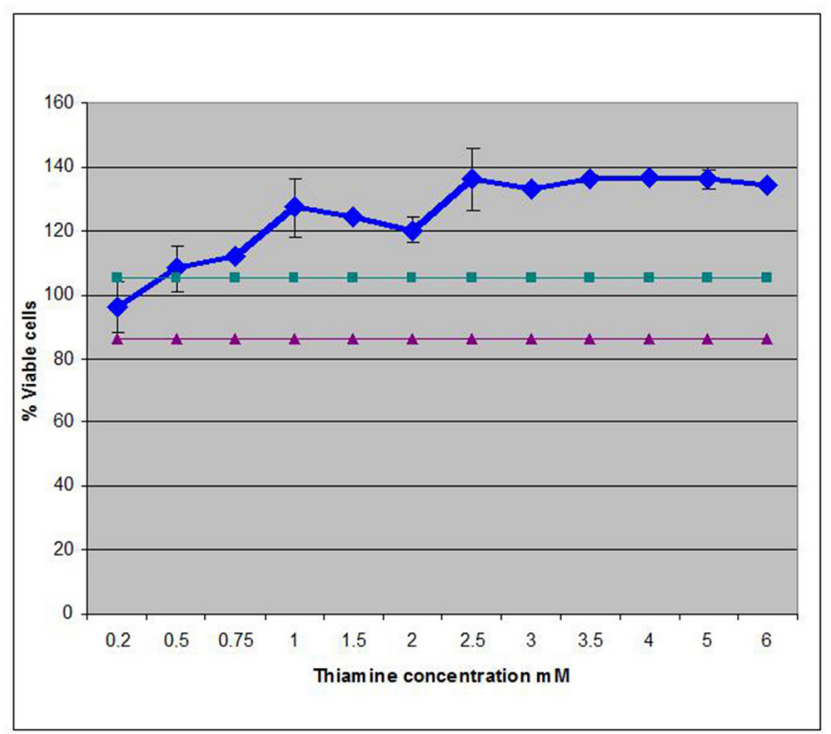

\section{Results}

\section{Cell viability}

To keep thiamine deficit conditions pyrithiamine hydrobromide, a competitive inhibitor of the thiamine transporter was used at the concentration $600 \mathrm{nM}$, which ensured ca. $80 \%$ of cell viability. The effectiveness of this concentration was proved in HPLC analysis as reducing the intracellular thiamine concentration below $1 \mathrm{ng} / \mathrm{mg}$ protein. As shown in Fig. 1, the significant increase in GM14467 viability to ca. $135 \%$ as referenced to the TDM level was caused by thiamine used at the $2.5 \mathrm{mM}$. Upon the higher concentration, plateau in the cell growth was noticed. In GM13509 growth stimulation ca. 165\% appeared upon thiamine supplementation at the $5.0 \mathrm{mM}$. For the higher thiamine concentrations, a decrease in GM13509 cells viability was observed (Fig. 2). At lower doses of thiamine, i.e. $0.5 \mathrm{mM}$ for GM14467 and $1.0 \mathrm{mM}$ for GM13509 the cell growth stimulation was comparable in both cell lines and reached the growth level as in the reference cultures TDM, i.e. ca. 100\% (Fig. 1 and 2).

\section{Intracellular thiamine concentration}

Both native cell lines were not different in the intracellular levels of thiamine and TDP, but the increase of the exogenous thiamine concentration was slightly reflected in the intracellular thiamine level. The GM14467 and GM13509 cells cultivated in deficit conditions (TDM, TDM Pyri) as well as the cells in the control cultures had the level of thiamine below $1 \mathrm{ng} / \mathrm{mg}$ protein and TDP between ca. $0.3-0.5$ $\mathrm{ng} / \mathrm{mg}$ protein. In GM14467, cells exposed to $0.5 \mathrm{mM}$ of
Fig. 2. Influence of thiamine supplementation on GM14467 cells. $\mathbf{\Delta}$ - the cells kept with pyrithiamine hydrobromide $(600 \mathrm{~nm})$ throughout the whole incubation time (4 days) (TDM Pyri), - the cells kept for 3 days with pyrithiamine and for the next $24 \mathrm{~h}$ in the intact RPMI 1640 (TDM); - the cells exposed to thiamine for $24 \mathrm{~h}$. Bars represent the mean \pm SD

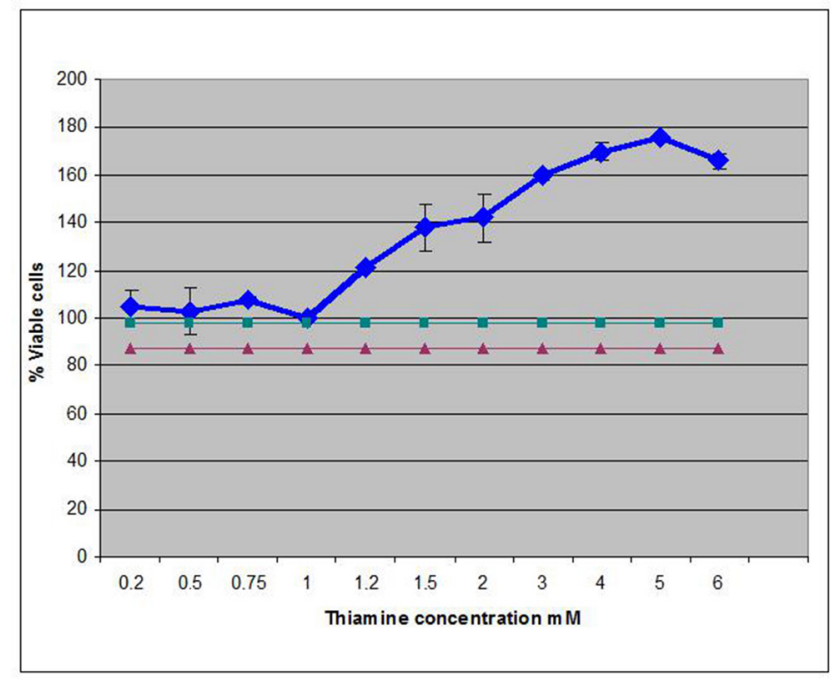

thiamine hydrochloride and in GM13509 cells exposed to $1.0 \mathrm{mM}$ of that compound the intracellular levels increased insignificantly above $3 \mathrm{ng} / \mathrm{mg}$ protein ( $\mathrm{p}>0.05$ ). The only significant increase of the intracellular thiamine level after treatment with exogenous thiamine hydrochloride was noted in GM13509 cells exposed to $5.0 \mathrm{mM}$ of that compound and reached $12.06 \mathrm{ng} / \mathrm{mg}$ protein as compared with the control cultures TDM and TDM Pyri ( $\mathrm{p}=0.0273$ and $\mathrm{p}=0.0216$, respectively).

The TDP levels upon exogenous thiamine were comparable in both kinds of cells but any correlation with the exogenous thiamine concentrations in the medium was not observed (data not shown).

\section{Profile of the genes related to thiamine and energy metabolism}

To identify genes that could usefully classify HD patients and healthy controls, 27 genes mostly related to thiamine and energy metabolism were selected for analysis with qRT-PCR technique (Table 1).

The differences in mRNA expression level were presented as GPR FC values and reflected the gene transcripts changes found in the GM13509 cells with mHTT in relation to control GM14467 cells. As shown in Table 2, the intact cells with expanded CAG fragment differed from normal cells in the higher expression of 3 genes: MDH1, GAPDH and SLC19A3 (GPR FC $1.3 \div 3.4$ ). The expression of DLD, IDH1, SDHA and SLC19A1 decreased in GM13509 cells cultured in thiamine deficit (TDM-Pyri) or upon low thiamine concentration (TDM) (GPR FC $-2.11 \div-1.28$ ), but the exogenous thiamine did not make any changes on mRNA levels of tested genes. Some genes, 
Table 2. Altered thiamine and energy metabolism related genes expression in lymphocytes B with mHTT (GM 13509)* compared with control lymphocytes B with normal HTT (GM 14467)** in deficit or presence of thiamine

\begin{tabular}{|c|c|c|c|c|c|c|c|c|c|c|}
\hline \multirow{2}{*}{$\begin{array}{c}\text { Gene } \\
\text { transcript }\end{array}$} & \multicolumn{2}{|c|}{ Control } & \multicolumn{2}{|c|}{ TDM-Pyri } & \multicolumn{2}{|c|}{ TDM } & \multicolumn{2}{|c|}{ Thiamine $1.0 * / 0.5 \mathrm{mM}^{* *}$} & \multicolumn{2}{|c|}{ Thiamine $5.0^{*} / 2.5 \mathrm{mM}^{* *}$} \\
\hline & GPR FC & $p$-value & GPR FC & p-value & GPR FC & $p$-value & GPR FC & $\mathrm{p}$-value & GPR FC & $p$-value \\
\hline ACO1 & -2.20 & 0.21 & -1.70 & 0.30 & -1.41 & 0.24 & -1.39 & 0.20 & 1.64 & 1.64 \\
\hline DBT & -1.65 & 0.15 & -1.17 & 0.11 & -1.52 & 0.10 & -1.51 & 0.03 & -1.18 & -1.18 \\
\hline DLAT & -1.66 & 0.20 & -2.17 & 0.07 & -1.41 & 0.03 & -1.22 & 0.04 & -1.00 & -1.00 \\
\hline DLD & -1.48 & 0.22 & -1.85 & 0.16 & -1.28 & 0.04 & -1.04 & 0.11 & 1.25 & 1.25 \\
\hline DLST & -1.85 & 0.36 & -2.43 & 0.08 & -1.54 & 0.17 & -2.38 & 0.00 & -1.84 & -1.84 \\
\hline GAPDH & 2.83 & 0.01 & 5.99 & 0.00 & 2.40 & 0.01 & 3.49 & 0.01 & 1.68 & 1.68 \\
\hline $\mathrm{IDH} 1$ & -2.21 & 0.27 & -2.38 & 0.17 & -1.39 & 0.03 & -2.05 & 0.87 & -1.12 & -1.12 \\
\hline $\mathrm{MDH} 1$ & 1.32 & 0.03 & -1.17 & 0.08 & 1.33 & 0.07 & 1.41 & 0.21 & 1.19 & 1.19 \\
\hline $\mathrm{OGDH}$ & -1.42 & 0.36 & -1.35 & 0.27 & -1.38 & 0.27 & -2.08 & 0.01 & -1.02 & -1.02 \\
\hline SDHA & -2.10 & 0.09 & -3.63 & 0.11 & -1.37 & 0.03 & -2.22 & 0.61 & -1.45 & -1.45 \\
\hline SLC19A1 & -1.40 & 0.51 & -2.11 & 0.01 & -1.22 & 0.28 & -1.45 & 0.20 & -1.18 & -1.18 \\
\hline SLC19A2 & -1.56 & 0.27 & -1.97 & 0.14 & -1.45 & 0.22 & -1.70 & 0.03 & 1.05 & 1.05 \\
\hline SLC19A3 & 3.44 & 0.01 & 8.37 & 0.03 & 1.61 & 0.03 & 6.86 & 0.02 & -1.13 & -1.13 \\
\hline SLC25A1 & 1.11 & 0.05 & -1.22 & 0.10 & 1.04 & 0.13 & 1.80 & 0.02 & 1.16 & 1.16 \\
\hline
\end{tabular}

Bolded GPR FC values with $p<0.05$ were considered significant.

such as: DBT, DLST, ACO1, OGDH, SLC19A2, SLC25A19 and DLAT in mutated cells showed lower mRNA expression than the normal B lymphocytes under thiamine supplementation to the medium (GPR FC $-2.38 \div 1.51$ ), but a deficit of the vitamin did not affect these genes. We have found only 2 genes whose expression answered both thiamine deficit and supplementation, i.e. GAPDH and SLC19A3. Increased expression of both in relation to the normal cells was observed in B lymphocytes HD which were kept in thiamine deficit conditions (TDMPyri) (ca. 6-fold GPR and above 8-fold GPR, respectively) and after thiamine supplementation at the concentration 1.0 mM (GAPDH - 3.5-fold GPR and SLC19A3 above 7-fold GPR). Thiamine used at a higher concentration, $5.0 \mathrm{mM}$, caused above a 1.5-fold decrease in GAPDH in GM13509 cells and a not significant difference in expression of SLC19A3 as compared to GM14467 cells.

\section{ATP synthesis}

The obtained results include a total ATP synthesis and ATP synthesized specifically in mitochondria, which was possible by the use of $1 \mathrm{mg} / \mathrm{mL}$ oligomycin, and $0.15 \mathrm{mM}$ Ap5A. ${ }^{11}$ Oligomycin is an inhibitor of mitochondrial ATP
Fig. 3. KGDHC activity expressed as a percentage of the control in the cultures kept under thiamine deficit (TDM Pyri and TDM) and under $24 \mathrm{~h}$ - thiamine supplementation, i.e. 0.5 and $2.5 \mathrm{mM}$ for GM14467 cells and 1.0 and $5.0 \mathrm{mM}$ for GM13509 cells. Bars represent mean \pm SD

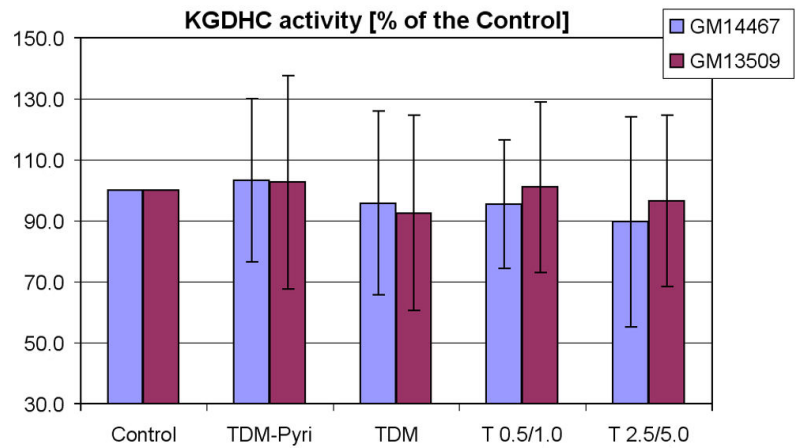

synthesis and Ap5A is an inhibitor of adenylate kinase, which inhibits direct ADP phosphorylation - one of the sources of ATP not specific for mitochondria. So, the rate of specific mitochondrial ATP synthesis was determined by the difference between the results obtained in the presence and absence of oligomycin and Ap5A, according to Marriage et al. ${ }^{13}$ 
Fig. 4. BCKDHC activity expressed as a percentage of the Control in the cultures kept under thiamine deficit (TDM Pyri and TDM) and under $24 \mathrm{~h}$ - thiamine supplementation, i.e. 0.5 and $2.5 \mathrm{mM}$ for GM14467 cells and 1.0 and 5.0 mM for GM13509 cells. Bars represent the mean \pm SD. Asterix indicates significant differences with the following $p$ values: ${ }^{*} p<0.05$; ${ }^{* *} p<0.01$; *** $p<0.001$

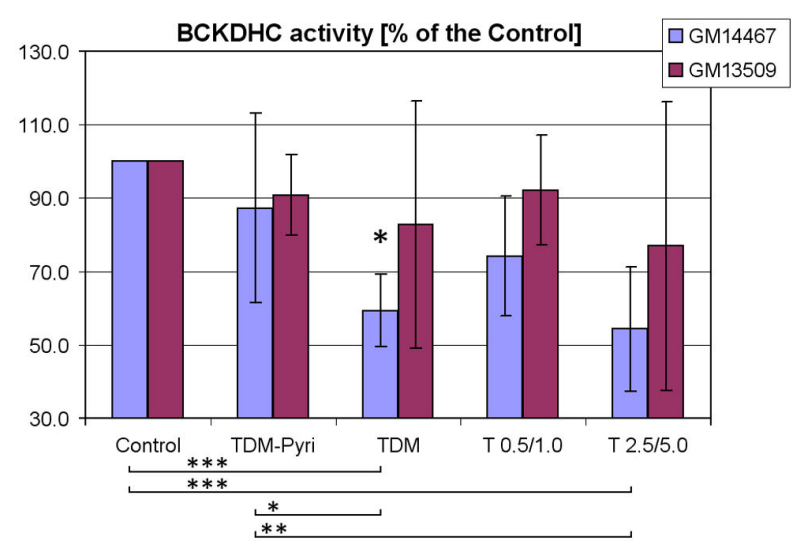

In this study, total ATP levels in the native GM13509 cells and GM14467 cells were similar $(257 \pm 26 \mathrm{ng} / \mathrm{mg}$ protein and $265 \pm 42 \mathrm{ng} / \mathrm{mg}$ protein, respectively, $\mathrm{p}>0.886$ ) and the exogenous thiamine did not stimulate total or specifically mitochondrial ATP synthesis significantly ( $p>0.05)$ (data not shown).

\section{KGDHC and BCKDHC activity}

As shown in Fig. 3, no significant differences in KGDHC activity were noticed between GM14467 and GM13509 cells in thiamine deficit conditions or under thiamine supplementation. The specific activity of this enzyme in the native cells was comparable: $13.20 \pm 2.19 \mathrm{nmol} /$ (min $\times$ mg protein) in GM14467 and $12.89 \pm 0.80 \mathrm{nmol} /$ $(\mathrm{min} \times \mathrm{mg}$ protein) in GM13509 cells $(\mathrm{p}>0.05)$. The cells were similar also in regard of the native BCKDHC specific activities, i.e. $2.88 \pm 0.87 \mathrm{nmol} /(\mathrm{min} \times \mathrm{mg}$ protein $)$ in GM14467 and $2.72 \pm 0.85 \mathrm{nmol} /(\mathrm{min} \times \mathrm{mg}$ protein $)$ in GM13509 cells ( $p>0.05$ ). The only significant difference between both cell types was found in TDM, in which BCKDHC had higher activity for GM13509 cells than for GM14467 cells (Fig. 4) ( $<$ 0.05). Thiamine deficit and supplementation did not affect BCKDHC activity in GM13509 cells. Surprisingly significant results were obtained in GM14467 cells, i.e. the 4-day treatment of these cells with pyrithiamine (TDM Pyri) did not result in the reduction of BCKDHC activity compared to the control. However, a significant decrease of BCKDHC activity was noticed in TDM (3 days with pyrithiamine and $24 \mathrm{~h}$ in the intact RPMI) as compared to control and to TDM Pyri ( $\mathrm{p}<0.001$ and $\mathrm{p}<0.05$, respectively). A higher dose of thiamine $(2.5 \mathrm{mM})$ caused a significant reduction of BCKDHC activity as compared to the control and to the cells kept under thiamine deficient condition, i.e. TDM Pyri ( $\mathrm{p}<0.001$ and $\mathrm{p}<0.01$, respectively), which suggests a negative correlation between BCKDHC activity and thiamine concentration in GM14467 cells.

\section{Discussion}

In this study we analyzed the influence of the exogenous thiamine supplementation on energy metabolism in human B lymphocyte cell lines in in vitro cultures. We studied the intracellular levels of thiamine and TDP under deficit and supplemented conditions, the profiles of the genes related to thiamine and the energy processes, ATP synthesis and the activities of some thiamine dependent enzymes included in the Krebs cycle as KGDHC and BCKDHC. All these parameters were defined at the concentrations of thiamine selected on the basis of cell viability tests as the stimulating the cell growth.

The use of pyrithiamine hydrobromide as a competitive inhibitor of the thiamine transporter resulted in the lowest intracellular thiamine concentrations defined under deficit conditions (below $1 \mathrm{ng} / \mathrm{mg}$ protein). ${ }^{14}$ The TDP values defined in our studies inside the native both cells (ca. $0.3-0.5 \mathrm{ng} / \mathrm{mg}$ protein) were similar to the levels determined in the other cells. ${ }^{15}$ These initial results obtained in B lymphocytes may suggest that the level of the phosphorylated form of thiamine is not a feature of the neurodegeneration phenotype. Bettendorff et al. obtained similar results in brains of patient with frontal lobe degeneration of the non-Alzheimer's type. ${ }^{16}$ The brain levels of the total thiamine, thiamine monophosphate (TMP) and TDP were also not significantly different from control values in the case of the patients with Friedreich's ataxia and spinocerebellar ataxia type $1 .{ }^{17}$ However, more studies are required on TDP intracellular levels to evaluate the reliability of the phosphorylation processes in the examined cells. Because of that, the results obtained in this study have been interpreted only with regard to the non-phosphorylated thiamine levels. Fig. 1 and 2 present that the stimulation of proliferation of GM13509 cells up to the $135 \%$, as compared to the reference culture (which is the maximal level of growth obtained in GM14467 cells at $2.5 \mathrm{mM}$ of thiamine), was reached at ca. $1.5 \mathrm{mM}$ of thiamine. These results can suggest increased growth potential of B lymphocytes with mHTT upon the exogenous thiamine.

The analysis of the genes connected with energy metabolism, which has been made in the intact B lymphocytes, showed that energy in fact may be one of the features of $\mathrm{HD}$, although the thiamine related genes did not seem to be a key point in the gene profile characterizing HD. Native GM13509 cells had a higher than GM14467 cell expressions of GAPDH gene encoding glyceraldehydes3-phosphate dehydrogenase (GADPH), which is involved in glycolysis and MDH1 gene that encodes malate de- 
hydrogenase (MDH1), one of the key enzymes of Krebs cycle. GAPDH binds specifically to huntingtin and the $\beta$-amyloid precursor protein in HD and Alzheimer's disease (AD), respectively, which may affect their functional diversity, including energy production. ${ }^{17}$ In fact, Mazzola and Sirover evidenced an impairment of GAPDH glycolytic activity of 27 and 33\% in AD and HD, respectively. ${ }^{18}$ According to other authors, the overexpression of GAPDH enhances nuclear translocation of $\mathrm{mHTT}$ and cytotoxicity. ${ }^{19}$ On the other side, some studies revealed another role of GAPDH, among others in transcription or posttranscriptional regulation, apoptosis, pointing to the role of that enzyme in neurodegenerative diseases, including HD. ${ }^{18}$

An interesting observation obtained in this study is that SLC19A3 gene, widely expressed and capable of transporting thiamine by the encoded protein, showed the increased expression (ca. 3.5-fold GPR) in the intact cells with mHTT towards control. ${ }^{20}$ The increase in GAPDH and SLC19A3 transcripts level was shown also in B lymphocytes with mHTT upon thiamine deficit and upon supplementation with $1 \mathrm{mM}$ of the vitamin, which is difficult to explain, especially in deficit conditions.

mRNA of the genes which encode the thiamine-related enzymes and the other enzymes involved in energy metabolism in human B lymphocytes upon thiamine deficit and consequently upon thiamine supplementation was not changed. This is in contradistinction to the claims made by other authors, who described lower mRNA of transketolase and E1 $\beta$ subunit of PDHC in thiamine deficient cultures of human lymphoblasts and fibroblasts. ${ }^{21}$ Strand et al. reported the decreased expression of IDH3A in skeletal muscles of R6/2 mice with $\mathrm{mHTT}$, which is a gene that encodes one of the isocitrate dehydrogenase isoenzymes, which participates in Krebs cycle. ${ }^{22}$ In our study, such an effect resulting from HD was not observed. Instead of this, the 2-fold decrease in the isocitrate dehydrogenase gene (IDH1) expression was noticed in GM13509 cells upon thiamine deficiency which suggests that low thiamine intracellular level could somehow be reflected in energy metabolism of peripheral tissues cells derived from HD subjects.

We did not observe the differences in the total ATP levels between the intact cells, which is partly consistent with Milakovic and Johnson, who reported decreased ATP synthesis only in mitochondria of clonal striatal cells established from $\mathrm{Hdh}^{\mathrm{Q} 7}$ (wild type) and $\mathrm{Hdh}^{\mathrm{Q} 111}$ (mutant huntingtin knock-in) mouse embryos but not total ATP. ${ }^{23}$

On the basis of our study, it can be said that an increase of cell viability observed in both types of cells after thiamine supplementation was not related to total or specifically mitochondrial ATP synthesis. Marriage et al. observed the $\mathrm{CoQ}_{10}$ but not of B-complex influence on ATP synthesis in peripheral lymphocytes. ${ }^{13}$ The authors pointed out that the beneficial effects of single vitamins have often been due to a relative deficiency of the vita- min or to a specific defect in an enzyme that utilizes the vitamin as a cofactor. It is also possible that the time exposure of the cells to thiamine used in our study was too short. Ham et al. in cerebral capillary cells observed the influence of thiamine on a metabolism after 3-7 days of incubation with the vitamin. ${ }^{24}$

Thiamine deficit can be reflected in the activities of thiamine dependent enzymes on the cellular level. The same potential benefits of exogenous thiamine or thiamine phosphates are studied especially in the neurodegenerative diseases because of the proved role of thiamine in the pathogenesis of many neurological syndromes. Thus, a decrease of $\mathrm{KGDHC}$, transketolase or PDHC activities during thiamine deficiency were found in autopsied brain tissue from neuropathologically proven AD patients. ${ }^{25}$ $30 \%$ inhibition of KGDHC was observed in rats' whole forebrain mitochondria after pyrithiamine exposure. ${ }^{26}$ Mastrogiacomo et al. measured the activity of KGDHC in postmortem brain samples from confirmed AD cases in both the presence and absence of TPP. ${ }^{27}$ In each brain area examined, TPP produced a greater stimulatory effect on KGDHC activity in AD group as compared with the controls. The consequences of thiamine deficit were discussed also in non-CNS tissues. ${ }^{28,29}$ Shi et al. indicated a region and time dependence of the KGDHC activity, mRNA and immunoreactivity of KGDHC subunits in response to thiamine deficit in brain tissues. ${ }^{30}$

On the other hand, KGDHC is not always susceptible to restoration. As shown by Blass et al. in cultured skin fibroblasts of DAT (dementia of the Alzheimer type) cases $\mathrm{KGDHC}$ and transketolase activities were reduced to $50-60 \%$ or $80-90 \%$ of normal, respectively but treatment with large doses of thiamine has not been beneficial. ${ }^{28}$

After analyzing the native activities of KGDHC and BCKDHC obtained in GM14467 and GM13509 cells in this study, no significant changes were found. As was shown by Krzysztoń-Russjan et al., BCKDK (branched chain ketoacid dehydrogenase kinase) on the transcription level was increased in nuclear blood cells of HD subjects. $^{31}$

In turn, no significant abnormalities of KGDHC were also indicated in red blood cells and cultured fibroblasts of AD. ${ }^{29}$ In this study the negative correlation noted between BCKDHC activity and thiamine concentration found in GM14467 cells is difficult to interpret, but it proves the cell specificity of energy metabolism.

\section{Conclusions}

B lymphocytes cell line obtained from HD subject seems to be more "sensitive" to the exogenous thiamine than control cells in relation to stimulation of cell growth, although they do not differ from control cells in energy metabolism expressed at the intracellular ATP level. This effect can be related to the increased intake of thiamine hydrochloride 
by the cells but not controlled by SLC19A3 gene and it is rather not related to energy metabolism dependent on thiamine. However, some differences in mRNA expression of the genes related to the thiamine and energy metabolism noticed between B lymphocytes, normal and HD prompt that thiamine can have a role in HD pathogenesis and that the supplementation of this vitamin may be important to improve the impaired energy metabolism in HD cells. More studies are needed to confirm these suggestions.

\section{References}

1. Mochel F, Haller RG. Energy deficit in Huntington disease: Why it matters. J Clin Invest. 2011;121:493-499.

2. Sassone J, Colciago C, Cislaghi G, Silani V, Ciammola A. Huntington's disease: The current state of research with peripheral tissues. Exp Neurol. 2009:219:385-397.

3. Arenas J, Campos Y, Ribacoba R, et al. Complex I defect in muscle from patients with Huntington's disease. Ann Neurol. 1998; 432(3):397-400

4. Schapira AHV. Mitochondrial involvement in Parkinson's disease, Huntington's disease, hereditary spastic paraplegia and Friedreich's ataxia. Biochim Biophys Acta. 1999;1410:159-170.

5. Gil-Mohapel J, Brocardo PS, Christie BR. The role of oxidative stress in Huntington's disease: Are antioxidants good therapeutic candidates? Curr Drug Targets. 2014;15(4):454-468.

6. Gibson GE, Zhang H. Interactions of oxidative stress with thiamine homeostasis promote neurodegeneration. Neurochem Int. 2002;40:493-504

7. Aikawa $\mathrm{H}$, Watanabe IS, Furuse $\mathrm{T}$, et al. Low energy levels in thiamine-deficient encephalopathy. I Neuropathol Exp Neurol. 1984;43(3):276-287.

8. Pekovich SR, Martin PR, Singleton CK. Thiamine deficiency decreases steady-state transketolase and pyruvate dehydrogenase but not a-ketoglutarate dehydrogenase mRNA levels in three human cell types. J Nutr. 1998;128:683-687.

9. Jhala SS, Hazell AS. Modeling neurodegenerative disease pathophysiology in thiamine deficiency: Consequences of impaired oxidative metabolism. Neurochem Int. 2011;58(3):248-260.

10. Akilesh S, Shaffer DJ, Roopenian D. Customized molecular phenotyping by quantitative gene expression and pattern recognition analysis. Genome Res. 2003;13(7):719-727.

11. Manfredi G, Yang L, Gajewski CD, Mattiazzi M. Measurements of ATP in mammalian cells. Methods. 2002;26:317-326.

12. Katsuki H, Yoshida T, Tanegashima C, Tanaka S. Improved direct method for determination of keto acids by 2,4-dinitrophenylhydrazine. Anal Biochem. 1971;43:349-356.

13. Marriage BJ, Clandinin MT, Macdonald IM, Glerum DM. Cofactor treatment improves ATP synthetic capacity in patients with oxidative phosphorylation disorders. Mol Genet Metab. 2004;81:263-272.

14. Pekovich SR, Poggi V, Martin PR, Singleton CK. Sensitivity to thiamine deficiency in cultures human cells in dependent on cell type and is enhanced in cells from thiamine-responsive megaloblastic anemia patients. Nutr Biochem. 1998;9:215-222.

15. Zangen A, Shainberg A. Thiamine deficiency in cardiac cells in culture. Biochem Pharmacol. 1997;54:575-582.

16. Bettendorff L, Mastrogiacomo F, Wins P, Kish SJ, Grisar T, Ball MJ. Low thiamine diphosphate levels in brains of patients with frontal lobe degeneration of the non-Alzheimer's type. J Neurochem. 1997;69(5):2005-2010.

17. Bettendorff L, Mastrogiacomo F, LaMarche J, Dozić S, Kish SJ. Brain levels of thiamine and its phosphate esters in Friedreich's ataxia and spinocerebellar ataxia type 1. Mov Disord. 1996;11(4):437-439.

18. Mazzola JL, Sirover MA. Reduction of glyceraldehydes-3-phosphate dehydrogenase activity in Alzheimer's disease and in Huntington's disease fibroblasts. J Neurochem. 2001;76(2):442-449.

19. Senatorov VV, Charles V, Reddy PH, Tagle DA, Chuang DM. Overexpression and nuclear accumulation of glyceraldehydes-3-phosphate dehydrogenase in a transgenic mouse model of Huntington's disease. Mol Cell Neurosci. 2003:22(3):285-297.
20. Ganapathy V, Smith SB, Prasad PD. SLC19: The folate/thiamine transporter family. Pflugers Arch. 2004;447(5):641-646.

21. Perluigi M, Poon HF, Maragos W, et al. Proteomic analysis of protein expression and oxidative modification in R6/2 transgenic mice. Mol Cell Proteomics. 2005;4:1849-1861.

22. Strand $A D$, Aragaki $A K$, Shaw $D$, et al. Gene expression in Huntington's disease skeletal muscle: A potential biomarker. Hum Mol Genet. 2005;14(13):1863-1876.

23. Milakovic T, Johnson GVW. Mitochondrial respiration and ATP production are significantly impaired in striatal cells expressing mutant huntingtin. J Biol Chem. 2005;280(35):30773-30782.

24. Ham D, Karska-Wysocki B. Energy and glucose pathways in thiamine deficient primary rat brain microvascular endothelial cells. Gen Physiol Biophys. 2005;24:467-474.

25. Héroux M, Raghavendra Rao VL, Lavoie J, Richardson JS, Butterworth RF. Alterations of thiamine phosphorylation and of thiamine-dependent enzymes in Alzheimer's disease. Metab Brain Dis. 1996;11(1):81-88.

26. Jankowska-Kulawy A, Bielarczyk H, Pawełczyk T, Wróblewska M, Szutowicz A. Acetyl-CoA deficit in brain mitochondria in experimental thiamine deficiency encephalopathy. Neurochem Int. 2010;57:851-856.

27. Mastrogiacomo F, Bergeron C, Kish SJ. Brain alpha-ketoglutarate dehydrogenase complex activity in Alzheimer's disease. J Neurochem. 1993;61(6):2007-2014.

28. Blass JP, Sheu KF, Cooper AJ, Jung EH, Gibson GE. Thiamin and Alzheimer's disease. J Nutr Sci Vitaminol. 1992;Spec no;401-404.

29. Gibson GE, Sheu KF, Blass JP, et al. Reduced activities of thiamine-dependent enzymes in the brains and peripheral tissues of patients with Alzheimer's disease. Arch Neurol. 1988;45(8):836-840.

30. Shi Q, Karuppagounder SS, Xu H, Pechman D, Chen H, Gibson GE. Responses of the mitochondrial alpha-ketoglutarate dehydrogenase complex to thiamine deficiency may contribute to regional selective vulnerability. Neurochem Int. 2007;50:921-931.

31. Krzysztoń-Russjan J, Zielonka D, Jackiewicz J, et al. A study of molecular changes relating to energy metabolism and cellular stress in people with Huntington's disease: Looking for biomarkers. J Bioenerg Biomembr. 2013;45(1-2):71-85. 